\title{
The level of happiness among garment factory employees and factors affecting it, in two selected garment factories
}

\author{
L P H Kodithuwakku ${ }^{1}$, C N Kodithuwakku ${ }^{1}$, S Kirushanth ${ }^{1}$, W Khandu ${ }^{1}$, Thashi Chang ${ }^{2}$ \\ ${ }^{1}$ Faculty of Medicine, University of Colombo, Sri Lanka \\ ${ }^{2}$ Department of Clinical Medicine, Faculty of Medicine, University of Colombo, Sri Lanka
}

\author{
Article Information \\ Total number of \\ Words 1887 \\ Tables 02 \\ Figures 03 \\ Authors have no conflicts of interests to \\ declare
}

Keywords:Sri Lanka, Garment factory employees, Happiness.

Date of submission: 10.02 .2107

Date of acceptance: 30.10.2017

DOI:http://doi.org/10.4038/cjms.v54i2.4809

\author{
Author responsible for \\ correspondence: \\ L.H.P.Kodithuwakku \\ No. 28, Pedris Road Colombo 03, Sri \\ Lanka \\ Tel: 0094773689995 \\ Email: lirajharsha@outlook.com
}

\author{
Abstract \\ Background \\ Happiness is a key factor in health and recently it has become the goal in most \\ human organizations as productivity improves with improved happiness.

\section{Objective} \\ To assess the level of happiness and factors affecting it among the workers in \\ two selected garment factories in the districts of Colombo and Gampaha.
}

\section{Methods}

A descriptive cross-sectional study was conducted among 127 workers in two garment factories situated in Colombo and Gampaha. A self-administered questionnaire was used to gather information on the demographic characteristics, job satisfaction, level of happiness and other selected variables. The data was analyzed using descriptive statistics and Chi-square test.

\section{Results}

Sixty three percent of the study population were in the highest category of the level of happiness indicated as "very happy". Among the factors assessed to affect happiness; positive associations were found with friendly working environment $(\mathrm{p}=0.02)$, job satisfaction $(\mathrm{p}=0.03)$ and current marital status $(p=0.01)$; while no associations were found for salary grade and number of job accidents.

\section{Conclusions}

There is satisfactory levels of happiness among garment factory workers in the selected study group. There is opportunity for further improvement in the level of happiness through manipulation of friendly working environment, job satisfaction and current marital status due to their positive correlation with the level of happiness.

\section{Background}

The world health organization (WHO) defines health as a state of complete physical, mental and social wellbeing and not merely the absence of disease or infirmity [1]. Happiness can be observed as either the seed or the consequence of better health.

There has been a recent change in the organizational and institutional policy goals worldwide to focus on happiness as a whole, making economic things only a means to achieve it [2].
In addition the newer expansion of "happyproductive worker" hypothesis to include psychological wellbeing; warrants higher levels of productivity and standards with higher levels of happiness [3].As a developing country this concept of happiness geared enhancement of productivity, will be an efficient and a convenient method for designing policies in Sri Lanka . Despite the evident need there has been only a few research efforts focusing on this, locally as well as globally.

\section{http://orcid.org/0000-0003-1803-3444}


Garment industry is the highest foreign exchange earner and the largest industrial employment generator in Sri Lanka. Due to the fact that the majority of the workforce in garment factories are young adults from all parts of the country; they are a vulnerable as well as a malleable population towards whom any positive interventions implemented would be a valuable investment both economically and socially for years to come. Previous studies have assessed work-load [4,5], professional support [5,6], training received [5], remuneration $[5,7]$, career development $[5,7,8]$ and working condition [5] as factors determining happiness at different occupational and social settings.

This study aimed to assess the level of happiness and factors affecting it among garment factory workers in Sri Lanka, in view of aiding better construction of policies and interventions to utilize and manipulate these factors for enhanced happiness and productivity and health.

\section{Method}

A cross sectional descriptive study was conducted in 2016 among 127employees at two purposively selected garment factories situated in the districts of Colombo and Gampaha. Ethical approval was obtained from the Ethics Review Committee of the Faculty of Medicine, Colombo and administrative approval to conduct the study was obtained from the respective factory management.

Employees aged between 18-55 years were selected by availability sampling and employees with less than 6 months of experience in the relevant factory, and workers who have been diagnosed to have chronic or psychotic illnesses were excluded.

A self-administered questionnaire, consisting of three segments was used.The questionnaire was originally proposed in English and later translated to Sinhala and Tamil languages, and backtranslated to English by an independent personto ensure integrity, consistency,coherent of the English, Sinhala and Tamil versions, Clarity of the questions, and for the comprehensiveness in terms of objectives.

The first two segments consisted of standard questionnaires used internationally which were comprehensive and easily understood.Selfadministrated Personal Wellbeing Index questionnaire - Adult (PWI-A) 2013 Edition [9] (first segment) consisted of nine questions and was used to assess the personal wellbeing of the participants. Each question was responded on a scale from 0 to 10 . "No satisfaction" was indicated by "0" while "complete satisfaction" was denoted by "10". The conversion of PWI scores, which have been derived from a $0-10$ response scale, was a simple summation of scores in each response in which a total mark was given out of 90.Job Satisfaction Survey [10] (JSS), (second segment) assessed 9 aspects of job satisfaction (Pay, Promotion, Supervision, Fringe benefits, Contingent rewards, Operating conditions, Coworkers, Nature of work, Communication) allocating 4 statements for each. This consisted of 17 positively worded statements and 19 negatively worded statements. Positively worded statements scored from " 1 " to "6" representing strongest disagreement to strongest agreement respectively and in the negatively worded statements this score was reversed so that " 1 " represented strongest agreement and " 6 " represented strongest disagreement. The total score ranged from 36 to 216.

The 3rd segment of the questionnaire was on basic characteristics of the participants. This consisted of 25 questions under five categories with 'Yes'/ 'No' answers and open questions to write the answers. This segment of the questionnaire was designed after perusing previous literature and opinions of experts on the subject. The questions were made simple and most were provided with structured responses. However, questions that were believed to generate diverse responses were provided with an open option which was later coded.

Prior to data collection informed written consent was obtained from all the participants. The questionnaires were provided to each participant in their preferred language and each question was read out and explained while allowing time for answering, to minimize errors due to ambiguity.

\section{Classification of level of happiness}

The independent variable Personal Wellbeing Index (Happiness index) score was categorized into 3 equal classes (Less happy: 0-30, Moderately happy: 31-60, Very happy: 61-90) for comparative assessment of the level of happiness.Since the frequency distribution for Happiness index was a left skewed curve the first 2 classes of Happiness index were combined into a single class (Happy: 060, Very happy: 61-90) for the purpose of statistical analysis of associations with the dependent variables. The theoretical possibility of a total score of " 0 " which denotes "Unhappy" was ignored in the classification nomenclature.

\section{Classification of level of Job satisfaction}

Similarly, the score for Job Satisfaction Survey followed a skewed distribution curve, thus the median average value of the score for Job Satisfaction Survey was taken as the cut off value for demarcating satisfaction and dissatisfaction. 


\section{Statistical analysis}

SPSS package [11] was used for data analysis. Chisquare test at the 0.05 significance level was used to assess whether each categorical variable had a significant relationship with the Happiness index scores of garment factory workers.

Summary of a selected set of the collected data and their statistical associations with happiness is presented in table 1 . The study sample consisted of 127 employees aged between 18-55 years. A total of 130 questionnaires were distributed and 127(98.46\%) total responseswere obtained.

\section{Result}

The frequency distribution of Happiness index was a left skewed curve; making the median average more representative of the sample. (Figure 1).

The highest numbers of average marks were scored to questions regarding spirituality, health, and safety while the least were scored to questions regarding satisfaction about feeling a part of the community, future security and personal relationships. (Figure 2)

Table 1 Selected summary of results and their associations with happiness

\begin{tabular}{|c|c|c|c|c|c|c|c|}
\hline \multirow[t]{2}{*}{ Characteristic } & \multirow[t]{2}{*}{ Number } & \multirow[t]{2}{*}{ Total } & \multicolumn{2}{|c|}{$\begin{array}{c}\text { Percentage of } \\
\text { happiness }\end{array}$} & \multicolumn{3}{|c|}{$\begin{array}{c}\text { Association with } \\
\text { happiness }\end{array}$} \\
\hline & & & Happy & $\begin{array}{l}\text { Very } \\
\text { happy }\end{array}$ & $\mathrm{X}^{2}$ & df & $\mathbf{p}$ \\
\hline \multicolumn{8}{|l|}{ Age, years } \\
\hline $18-30$ & 81(63.8) & 127 & $31(38.2)$ & $50(61.8)$ & 0.49 & 2 & 0.78 \\
\hline $31-43$ & $32(25.2)$ & & $12(37.5)$ & $20(62.5)$ & & & \\
\hline $45-56$ & $14(11.0)$ & & $4(28.6)$ & $10(71.4)$ & & & \\
\hline \multicolumn{8}{|l|}{ Sex } \\
\hline Female & 115(90.6) & 127 & $41(35.7)$ & $74(64.3)$ & 0.96 & 1 & 0.327 \\
\hline Male & $12(9.4)$ & & $6(50)$ & $6(50)$ & & & \\
\hline \multicolumn{8}{|l|}{ Marital status } \\
\hline Married & $59(46.5)$ & 127 & $15(25.4)$ & $44(74.6)$ & 6.34 & 1 & 0.01 \\
\hline Unmarried & $68(53.5)$ & & $32(47)$ & $36(53)$ & & & \\
\hline \multicolumn{8}{|l|}{ Amount of salary } \\
\hline Low & $56(47.5)$ & 118 & $23(41)$ & $33(59)$ & 0.722 & 2 & 0.697 \\
\hline Mid & $34(28.8)$ & & $14(41.2)$ & $20(58.8)$ & & & \\
\hline High & $28(23.7)$ & & $9(32.1)$ & 19(67.9) & & & \\
\hline \multicolumn{8}{|l|}{ History of job accidents } \\
\hline Yes & $17(13.4)$ & 127 & $4(23.5)$ & 13(76.5) & 1.53 & 1 & 0.216 \\
\hline No & $110(86.6)$ & & $43(39)$ & $67(61)$ & & & \\
\hline \multicolumn{8}{|c|}{ Friendly working environment } \\
\hline Yes & $124(97.6)$ & 127 & $44(35.5)$ & $80(64.5)$ & 5.23 & 1 & 0.022 \\
\hline No & $3(2.4)$ & & $3(100)$ & 0 & & & \\
\hline \multicolumn{8}{|l|}{ Job satisfaction } \\
\hline Unsatisfied & $60(47.2)$ & 127 & $28(46.7)$ & $32(53.3)$ & 4.551 & 1 & 0.033 \\
\hline Satisfied & $67(52.8)$ & & $19(28.4)$ & $48(71.6)$ & & & \\
\hline
\end{tabular}




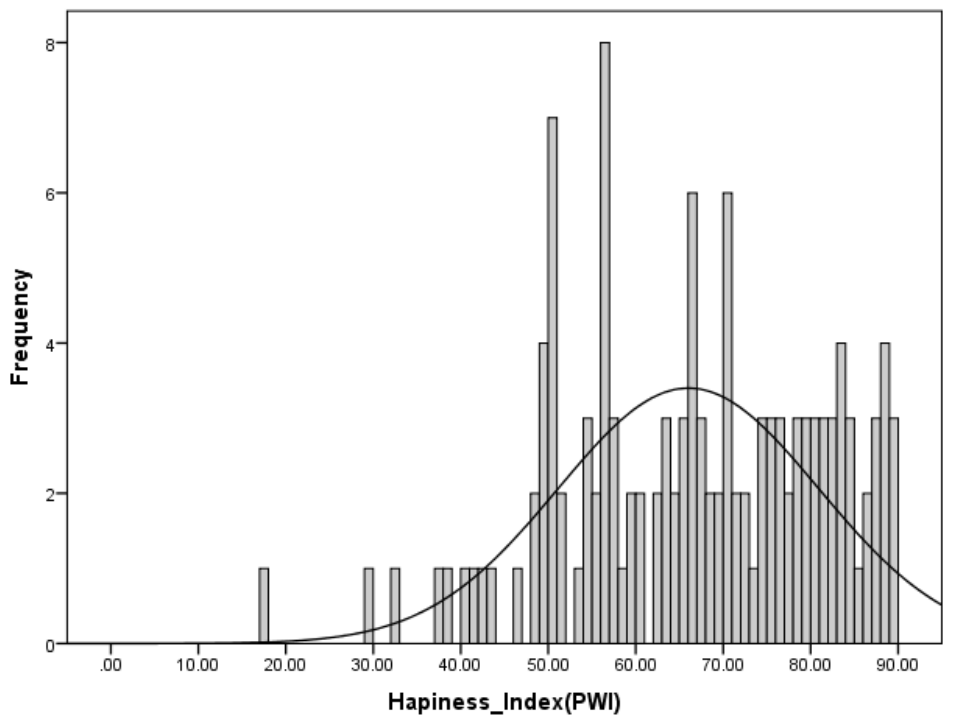

Figure1.Frequencycurvefor Happinessindex

(Mean:66.02,Median:67.00,Mode:56.00,Std.Deviation:14.89,Range:72.00)

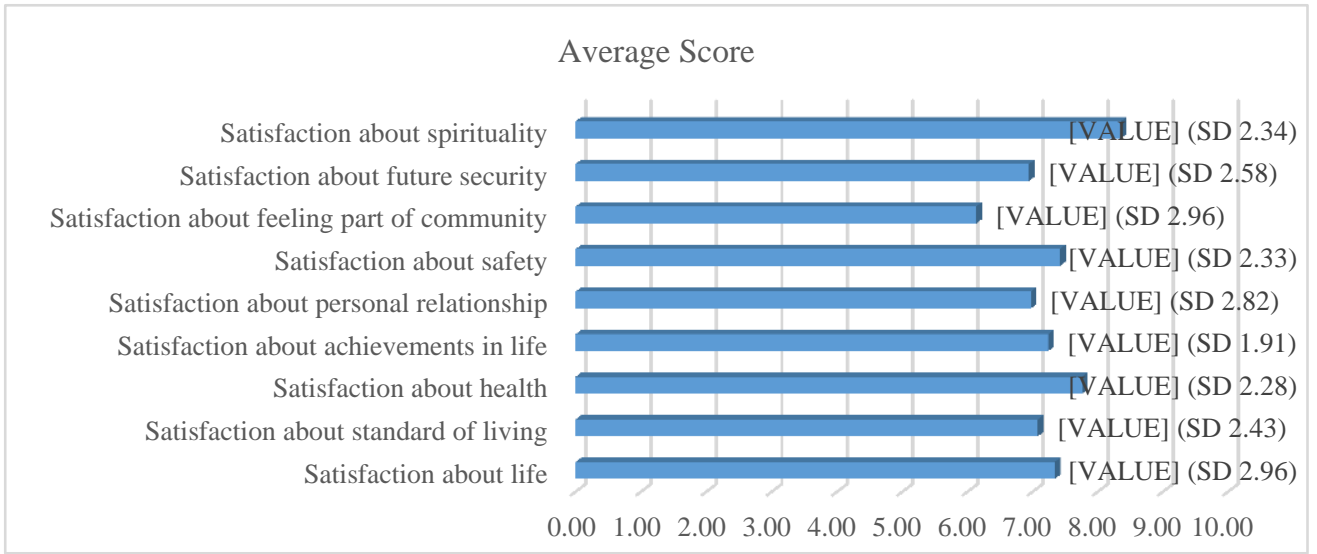

Figure 2.Average scores for each Personal Wellbeing Index (PWI)question

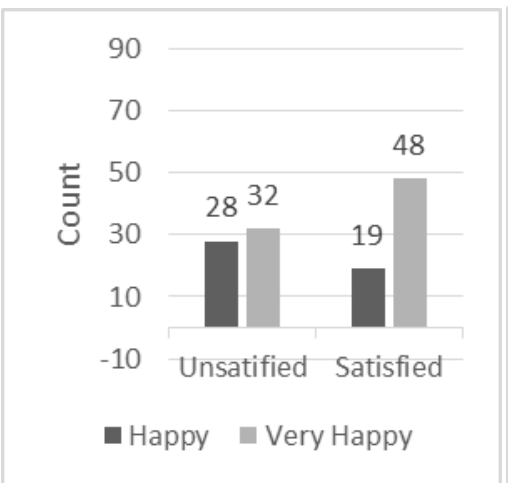

(a)

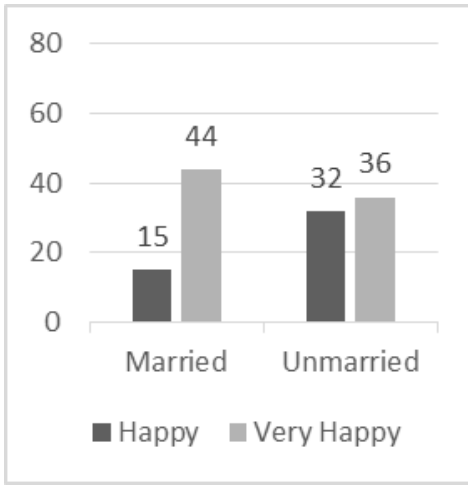

(b)

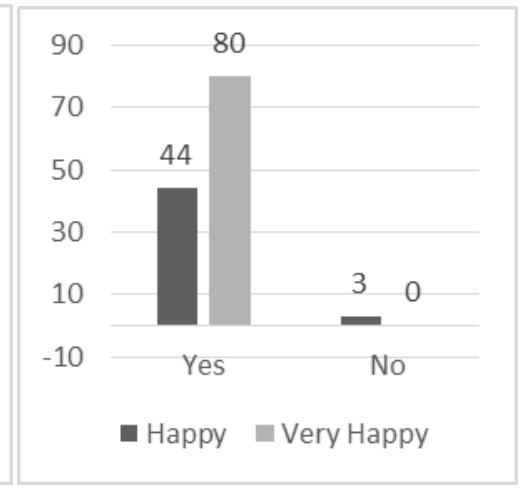

(c)

Figure3. (a)Distributionof studysampleby levelof happinessand jobsatisfaction, $\left(\chi^{2}=4.551 ; \mathrm{df}=1 ; \mathrm{p}=0.03\right.$ )

(b) Distribution ofstudysample by level of happiness and current marital status. $\left(\chi^{2}=6.343 ; \mathrm{df}=1 ; \mathrm{p}=0.01\right.$ ),

(c) Distributionof study sample by levelofhappinessand friendlyworkingenvironment $\left(\chi^{2}=5.230\right.$; $\left.\mathrm{df}=1 ; \mathrm{p}=0.02\right)$ 
There was a statistically significant association between level of happiness and; job satisfaction $(p=0.03)$, current marital status $(p=0.01)$ and friendly working environment $(p=0.02)$. Being in a marital relationship, a higher job satisfaction and a friendlier working environment were independently associated with higher levels of happiness. (Figure 3)

No significant association with Happiness index score was found with the variables; age, highest level of education, district of permanent residence, current residence, satisfaction about current residence, frequency of home visits, being the bread winner of the family, number of dependents in the family, number of working hours, level of experience, history of job accidents, participation in welfare activities, salary grade and amount of salary.

The statistical significance for its associations was not calculated for the variables; sex, ethnicity and current health status due to non-existentor very small variation of the variable within the study sample. (Table 2).

Table 2 Summary of variables and their associations with happiness

\begin{tabular}{|c|c|}
\hline Significant association with Happiness index & No significant association with Happiness index \\
\hline Current marital status & Age \\
\hline Friendly working environment & Highest level of education \\
\hline Job satisfaction & District of permanent residence \\
\hline \multirow{2}{*}{ Statistical associations with Happiness index not calculated* } & Current residence \\
\hline & Satisfaction about current residence \\
\hline Sex & Frequency of home visits \\
\hline Ethnicity & Being the breadwinner in the family \\
\hline \multirow[t]{7}{*}{ Current health status } & Number of dependents in the family \\
\hline & Number of working hours \\
\hline & Level of experience \\
\hline & History of job accidents \\
\hline & Participation in welfare activities \\
\hline & Salary grade \\
\hline & Amount of salary \\
\hline
\end{tabular}

*The associations for these variables were not calculated due to non-existent or minimal variation of the variables within the study sample.

\section{Discussion}

Our study highlighted the preferable base line level of happiness (63\% scoring between $61-90$ in the Happiness index) among garment factory employees in the sample population and further dissection of this data revealedth at the highest marks were scored in questions regarding; spirituality, health and safety. These higher scored items may be related to cultural perspectives of Sri Lankans and a higher sense of health and safety. The latter is thought to be due to a predominance of young adults in the study population. The study also illustrated short comings of the occupation where there are limited opportunities for interaction beyond the working environment, higher job specificity and limited career ladder; leading to the lowest marks being scored in questions regarding; satisfaction about feeling part of the community, future security and personal relationships.
Our study findings demonstrating a positive association between friendly working environment and job satisfaction on happiness were supported by previous studies carried out both in Sri Lanka [5] and in the USA [6] in the contex to fnursing staff. No significant associations were found between happiness and; sex, salary grade and number of job accidents; which was in contrast to the findings of some priorre search [7, 12]. Direct comparison is not possible due to the absen ceofany, which studieda similartar get population.

The a for ementioned differences between this study and others may be due to female pre dominance of the study sample (under representing the male sex), minimal variation of salary grades within each facility, confiding details about job accidents, the smaller sample size, sample population being acquired only from 2 factories in western province. It may also be due to use of Chisquare test to assess statistical significance of 
associations between the scalar variable (Happiness index) and other categorical variables. Though face and content validity were established prior to use, PWI and JSS has not been validated for Sri Lanka in a comprehensive validation study, thus findings based on these should be cautiously interpreted. These limitations may restrict the feasibility of extrapolation and generalization of the results to all garment factory employees in Sri Lanka.

\section{Conclusion and recommendations}

There is a preferable high baseline level of happiness among the employees of two garment factories in Sri Lanka. Higher level of happiness was positively associated with being in a marital relationship, friendly working environment, job satisfaction. Happiness was not associated with sexuality, salary grade and number of job accidents. Focusing on these three main areas; friendly working environment, marital status and job satisfaction is suggested for a higher level of happiness and higher productivity in garment industry. Effective interventions for improving these three variables should be assessed in future research. A larger study sample will help to generalize the finding further.

\section{Acknowledgements}

-Department of Community Medicine, Faculty of Medicine, University of Colombo. This research was carried out as a requirement of the Community Stream undergraduate academic programme

-Dr. NMCK Arambepola, MBBS MSc (Community Medicine) MD (Community Medicine) for providing statistical guidance.

\section{References}

1. Constitution of WHO: principles. World Health Organization. [Cited 2017 October] Available from: http://www.who.int/about/mission/en/

2. Oswald AJ. Happiness and economic performance. Econ.J. 1997;107(445):1815-31.

3. Wright T A, Cropanzano R. Psychological wellbeing and job satisfaction as predictors of job performance. J Occup Health Psychol. 2000; 5(1):84-94.

4. Cooper L C, Phillip J D, O’Driscoll P M, Organizational Stress, Sage Publications. 2001; (1).

5. Sridharan S, Liyanage U, Wickramasinghe S C. Impact of individual factors on job satisfaction of nursing officers in Sri Lankan government hospitals.2008;14(1):48-70.

6. McNeese- Smith K D. A content analysis of staff nurse description of job satisfaction and dissatisfaction. J AdvNurs. 1999; 29(6):1332-41.

7. Luthans F. Organizational Behavior. McGrawHill publications. 2001; (9).
8. Chu C I, Hsu $\mathrm{N}$ M, Price J L, et al. Job satisfaction of Hospital Nurses- an empirical test of a casual model in Taiwan. International Council of Nurses. IntNurs rev. 2003:176-182.

9. Personal Wellbeing Index - Adult (PWI-A) (English). Australian Centre on Quality of Life. [Cited 2015 July]. Available from: http://www.acqol.com.au>iwbg>pwi-a -english

10. Spector P E. Instructions for Scoring the Job Satisfaction Survey. JSS. Department of Psychology. University of South Florida. [Cited 2017 July]. Available from: http://http://shell.cas.usf.edu/ pspector/scales/jsspa g.html

11. IBM SPSS. IBM Analytics. [Cited 2015 August]. Available from: http://www01.ibm.com/software/analytics/spss/products/statist ics/,IBM SPSS Statistics, version 20.

12. Wijesinghe C P, Dissanayake S A W, Dissanayake P V L N. Survey of psychiatric morbidity in a semiurban population in Sri Lanka. ActaPsychiatr Scand. 1978;(58):413-441. 